Article

\title{
Drug Use before and during Pregnancy in Japan: The Japan Environment and Children's Study
}

\author{
Hidekazu Nishigori ${ }^{1}$, Taku Obara ${ }^{2,3,4, *}$, Toshie Nishigori ${ }^{1,3}$, Hirohito Metoki ${ }^{3,4,5}$, \\ Mami Ishikuro ${ }^{3,4}$, Satoshi Mizuno ${ }^{3}$, Kasumi Sakurai ${ }^{3}$, Nozomi Tatsuta ${ }^{3}$, Ichiko Nishijima ${ }^{3,4}$, \\ Ikuma Fujiwara $^{3}$, Takahiro Arima ${ }^{3}$, Kunihiko Nakai ${ }^{3}$, Nariyasu Mano ${ }^{2}$, \\ Shinichi Kuriyama ${ }^{3,4,6}$, Nobuo Yaegashi ${ }^{1,3,4}$ and Japan Environment \& Children's Study Group \\ 1 Department of Obstetrics and Gynecology, Tohoku University Graduate School of Medicine, Miyagi 9808574, \\ Japan; nishigori@med.tohoku.ac.jp (H.N.); toshienishigori@yahoo.co.jp (T.N.); \\ yaegashi@med.tohoku.ac.jp (N.Y.) \\ 2 Department of Pharmaceutical Sciences, Tohoku University Hospital, Miyagi 9808574, Japan; \\ mano@hosp.tohoku.ac.jp \\ 3 Environment and Genome Research Center, Tohoku University Graduate School of Medicine, \\ Miyagi 9808575, Japan; hmetoki@med.tohoku.ac.jp (H.M.); m_ishikuro@med.tohoku.ac.jp (M.I.); \\ samizuno@med.tohoku.ac.jp (S.M.); kasakurai69@gmail.com (K.S.); nozomi@med.tohoku.ac.jp (N.T.); \\ nishiji@@med.tohoku.ac.jp (I.N.); ifujiwara-endo@umin.ac.jp (I.F.); tarima@med.tohoku.ac.jp (T.A.); \\ nakaik@med.tohoku.ac.jp (K.N.); kuriyama@med.tohoku.ac.jp (S.K.) \\ 4 Tohoku Medical Megabank Organization, Tohoku University, Miyagi 9808575, Japan \\ 5 Department of Public Health and Hygiene, Tohoku Medical and Pharmaceutical University School of \\ Medicine, Miyagi 9818558, Japan \\ 6 International Research Institute of Disaster Science, Tohoku University, Miyagi 9808575, Japan \\ * Correspondence: obara-t@hosp.tohoku.ac.jp; Tel.: +81-22-717-7548
}

Academic Editor: Jeffrey Atkinson

Received: 20 October 2016; Accepted: 5 April 2017; Published: 10 April 2017

\begin{abstract}
Purpose: To elucidate drug use before and during pregnancy in Japan. Methods: The Japan Environment and Children's Study (JECS) is an ongoing nationwide birth cohort study. We analyzed data from JECS involving cases where drugs were used for 12 months before pregnancy was diagnosed, between the time of diagnosis of pregnancy until week 12 of pregnancy, and after week 12 of pregnancy. Results: We analyzed data from 97,464 pregnant women. The percentages of pregnant women who had taken one or more drugs and supplements before diagnosis of pregnancy, between the time of diagnosis of pregnancy until week 12 of pregnancy, and after week 12 of pregnancy, were $78.4 \%, 57.1 \%$, and $68.8 \%$ respectively. Excluding iron supplements, folic acid, and other vitamins and minerals, the percentages of women taking supplements were $75.3 \%, 36.0 \%$, and $51.7 \%$ at each respective time point. The following drugs and supplements were frequently used for 12 months before pregnancy diagnosis: Commercially available antipyretics, analgesics, and/or medicine for treating common cold (34.7\%), antipyretics, analgesics, and/or medicine for treating common colds, which were prescribed in hospitals (29.8\%), antimicrobial drugs (14.0\%), and anti-allergy drugs (12.5\%). The following drugs and supplements were frequently used from the time of pregnancy diagnosis until week 12 of pregnancy, and after week 12 of pregnancy: folic acid $(28.9 \%$ and $26.2 \%)$, antipyretics, analgesics and/or medicines for treating common cold, that were prescribed in hospitals (7.8\% and $13.3 \%)$, Chinese herbal medicines $(6.0 \%$ and $9.4 \%$, and uterine relaxants $(5.1 \%$ and $15.2 \%$ ). Conclusions: The analysis of a nationwide cohort study showed that a high percentage of Japanese pregnant women were taking medicinal drugs. Further research is required to elucidate the relationship between drug use during pregnancy and birth defects in Japan.
\end{abstract}

Keywords: pregnancy; medication use; supplement use 


\section{Introduction}

A number of drugs are known to exert latent harm on pregnant women and their fetuses [1]. According to previous studies on drug use in pregnant women, $40 \%-90 \%$ of these women take at least one drug [2-24]. A study found that the use of a single drug acting on the central nervous system was not related to congenital abnormalities; however, the use of multiple such drugs presented a higher risk of congenital abnormalities [25]. Therefore, it is important for surveys to be conducted on multidrug use and drug use in pregnant women.

In the Japanese health system, patients mainly obtain their prescribed drugs from community-based pharmacies, based on a prescription made by a doctor in a community clinic or hospital. Patients can also buy over-the-counter drugs in most community pharmacies. To the best of our knowledge, there has been no study based on a large-scale birth cohort survey in Japan. Therefore, there is little information about drug use and safety during pregnancy in Japan, and data from western countries have had to be used.

To elucidate the status of drug use by pregnant women, we analyzed a dataset from the Japan Environment and Children's Study, which focused on drug use before and during pregnancy in approximately 100,000 Japanese women.

\section{Methods}

\subsection{Study Settings and Subjects}

In January 2011, the Japanese Ministry of Environment launched a large-scale cohort epidemiological research project entitled the Japan Environment and Children's Study (JECS) [26]. JECS is an ongoing nationwide birth cohort study. The plan was to recruit approximately 100,000 pregnant women and their partners over a period of 3 years (i.e., 33,333 per year, which is around 3\% of Japanese newborns), collect biological samples, and conduct follow-ups for their children until they reach 13 years of age. The eligibility criteria for participants (expecting mothers) were as follows: (1) They should reside in the study areas at the time of the recruitment, and would be expected to reside continually in Japan for the foreseeable future, (2) expected delivery date should be between 1 August 2011 and mid-2014, and (3) they should be capable to participate in the study without difficulty, i.e., they must be able to comprehend the Japanese language and complete the self-administered questionnaire. Those residing outside the study areas, even if they visited the cooperating health care providers within the study areas, were excluded from the study.

The JECS protocol has been published elsewhere [26], and was approved by the Ministry of Environment's Institutional Review Board on Epidemiological Studies on 6 April 2010 (no. 100406001), as well as by the Ethics Committees for all participating institutions. Written informed consent was obtained from all participating women and their families. For the JECS, participants were recruited through the 15 Regional Centers located in Hokkaido, Miyagi, Fukushima, Chiba, Kanagawa, Koshin, Toyama, Aichi, Kyoto, Osaka, Hyogo, Tottori, Kochi, Fukuoka, and South Kyushu and Okinawa (Figure 1). Registration for JECS was open between January 2011 and March 2014 for pregnant women on a nationwide basis, and the required data were recorded. In total, about 100,000 pregnant women were enrolled between January 2011 and March 2014. 


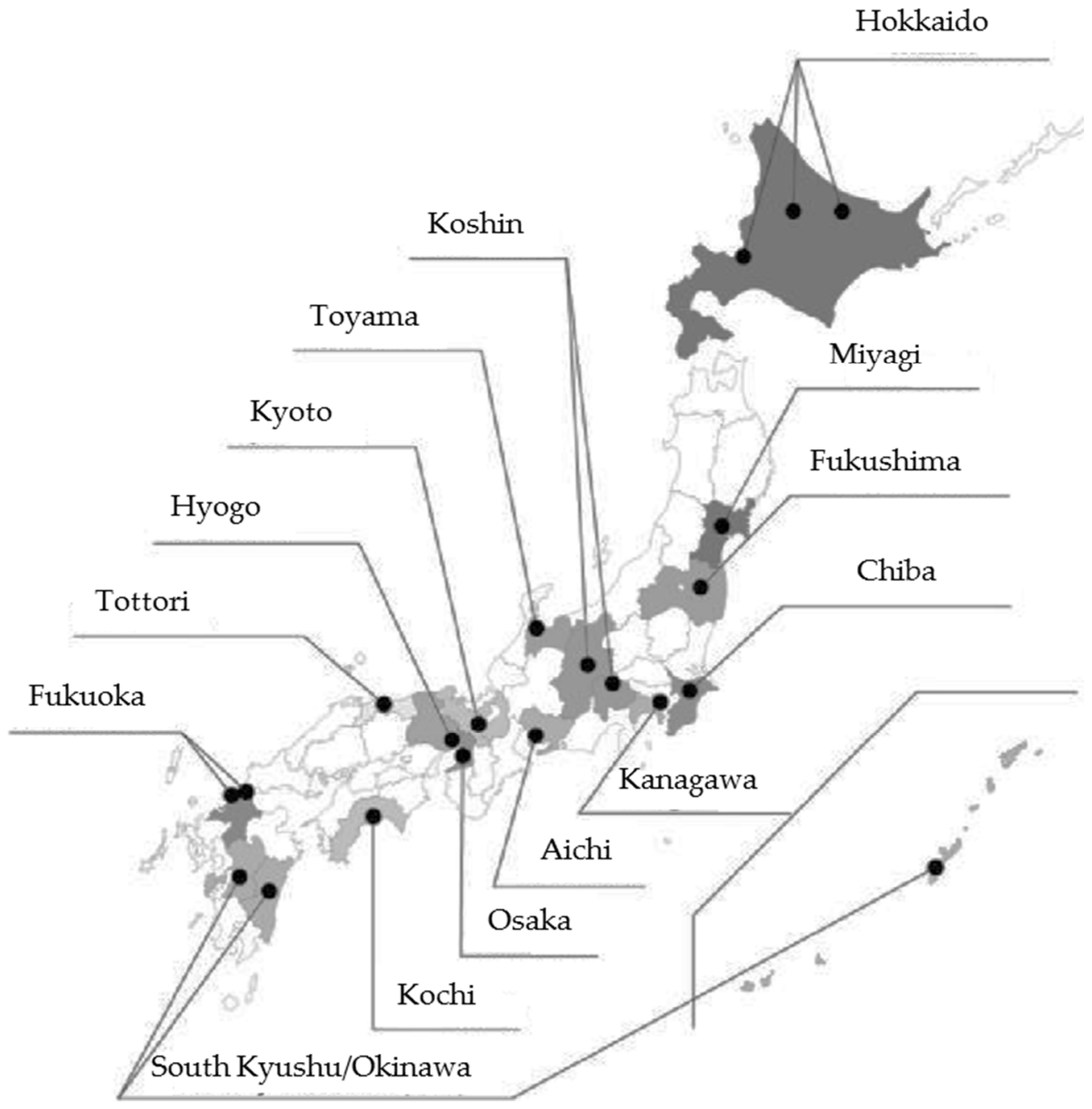

Figure 1. Location of the 15 Regional Centers of the Japan Environment and Children's Study (JECS). The participants were recruited through the 15 regional centers covered by the JECS.

The expected date of delivery was determined by comparing the expected date calculated from the crown rump length (CRL) at 8-11 pregnancy weeks, and the one calculated from the last menstrual period. Also, the expected date was calculated from biparietal diameter (BPD) for participants after the correction period with the CRL (around 8-11 weeks) or whose CRL $>4 \mathrm{~mm}$. In the case where there was a gap of seven or more days between the expected date of delivery calculated from the start of the last menstrual period and the one calculated from the CRL, the one calculated from the CRL value was adopted. In the case where there was a gap of 10 or more days between the expected dates of delivery as calculated from the start of the last menstrual period and the date calculated from the BPD, the one calculated from the BPD value was adopted.

The present study was based on the data set jecs-ag-20160426, which was released in June 2016. We analyzed this primary dataset from 104,102 records (Figure 2). The data set was created using children as the base. For example, in the case of twin pregnancies, two records (one each for the first and second child) were created for each pregnant woman. Because this study investigated pregnant women, in the case of multiple pregnancies, the records of children beyond the first child were excluded. We analyzed the data from pregnant women who had participated in both "In-T1" and "In-T2" interviews. Of 104,102 records in the jecs-ag-20160426 dataset, the records from 97,464 were analyzed. 


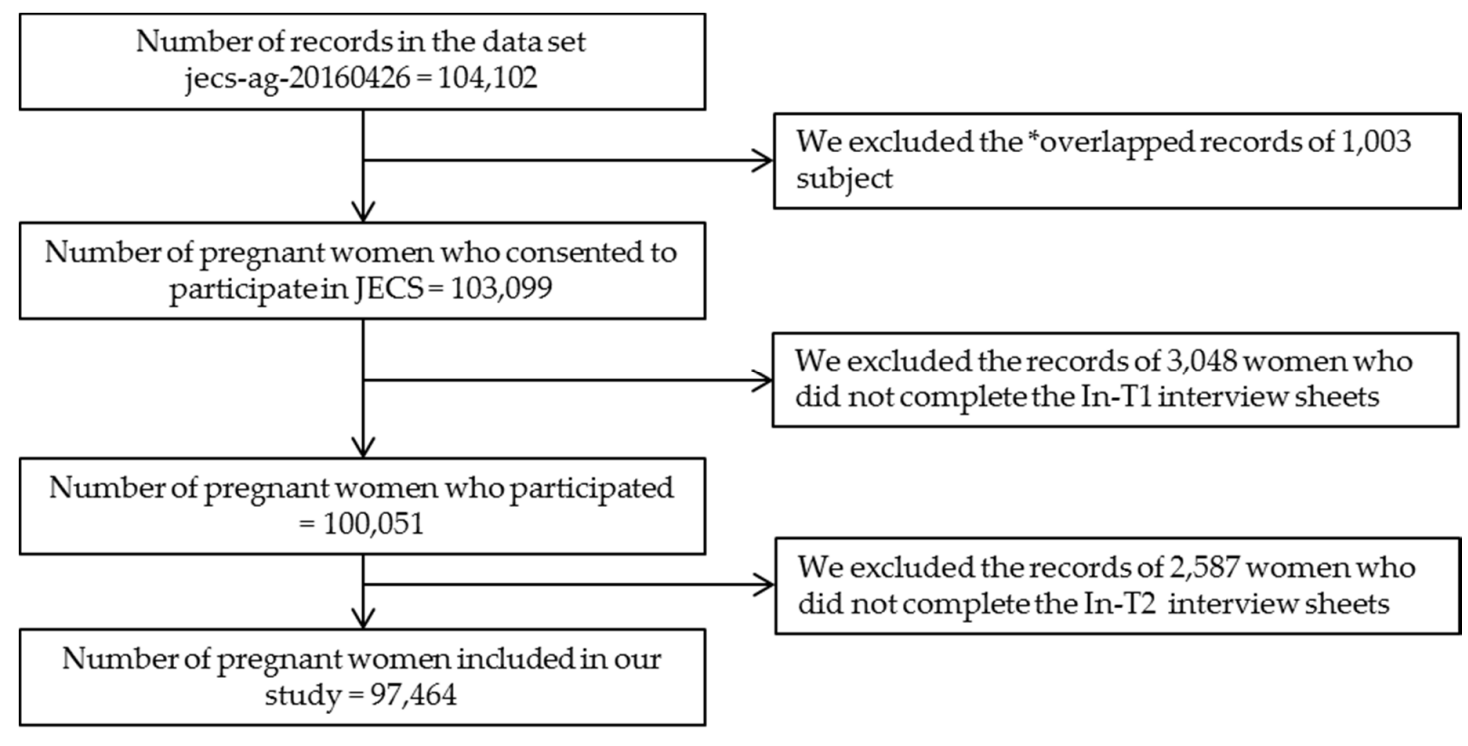

Figure 2. The study analyzed 97,464 pregnant women and provided the raw data for the JECS.

* Overlapped records: In the case of multiple pregnancy, the records beyond the first child were excluded.

\subsection{Data Collection}

All data on drug use were obtained based on two interviews: The "In-T1" interview was performed upon enrollment for mothers during the maternal first trimester or the second trimester (see Appendix A), and the "In-T2" interview was performed during the second or third trimester (see Appendix B). With respect to responses to interviews regarding drug use: During "In-T1" and "In-T2", a survey was performed by research coordinators through a face-to-face interview for pregnant women, and information was collected from a set medication list (see Appendix $C$ for the full list).

Drug use information was collected during each of the following time periods: (1) Before pregnancy diagnosis (drug use during the 12 months before pregnancy diagnosis), (2) Before week 12 of pregnancy (drug use from pregnancy diagnosis until Week 12 of pregnancy), and (3) After week 12 of pregnancy (drug use from week 12 of pregnancy until the time of the "In-T1" or "In-T2" interview). At period (1), drug use information was collected at the "In-T1" interview. In periods (2) and (3), drug use information was collected at both the "In-T1" and "In-T2" interviews. If a response was recorded at either In-T1 or In-T2, drug use was defined as present.

The gestation week of the In-T1 and In-T2 interviews were calculated back from the date of childbirth, the date of "In-T1" and "In-T2" interview, and the gestation week of birth based on the data set jecs-ag-20160426. Because only the year and month were provided for the dates of childbirth and the dates of the "In-T1" and "In-T2" interviews, the day was defined as the first of the month in all cases.

All data for the study were obtained from the following questionnaires: The "M-T1" questionnaire was performed upon enrollment for mothers during the maternal first or second trimester (M-T1), the "M-T2" questionnaire was performed for mothers during the second or third trimester (M-T2), the "Dr-T1" medical chart review was carried out by a doctor upon enrollment (Dr-T1), and the "Dr-0m" medical chart review was carried out by a doctor immediately after delivery (Dr-0m).

\subsection{Data Analysis}

Based on the M-T1, Dr-T1, M-T2, and Dr-0m questionnaires, the frequency and proportion of pregnant females were calculated, with a focus on the following items: gestation (weeks) of M-T1, gestation (weeks) of M-T2, age, marital status, education, family income, body mass index, smoking, alcohol consumption, parity, fertility treatment, history of spontaneous abortion, history of mental 
health disorders, hypertension, diabetes, mental health disorders, other pregnancy complications, hypertensive disorders of pregnancy, gestational diabetes, and other obstetric labor complications.

We analyzed the percentages of pregnant women who had taken one or more drugs, excluding supplements such as those for iron, folic acid, and other vitamins and minerals.

All analyses were performed using SAS statistical software, Version 9.4 (SAS Institute Inc., Cary, NC, USA).

\section{Results}

The participants of the 15 Regional Centers of JECS are shown in Table 1. The participants of JECS were distributed nationwide from the north, Hokkaido, to the south, Okinawa. The total number of interviewees in the JECS survey was around 130,000 pregnant women between January 2011 and March 2014, and the number of agreements was 103,099 pregnant women, so the agreement ratio was around $79 \%$. Agreement ratios for each Regional Center have not been determined at this time. In the present analysis, the study population consisted of 104,102 pregnant women. A total of 6638 pregnant women were excluded because of overlapped records for multiple pregnancies, and incomplete "In-T1" and "In-T2" interviews. Thus, we studied 97,464 pregnant women (Figure 2). Characteristics of subjects are shown in Table 2. The mean age and median gestation time of In-T1 and In-T2 in the subjects was 30.8 years, 15.7 weeks, and 27.6 weeks respectively. The median gestation time of M-T1 and M-T2 in the subjects was 15.4 weeks, and 27.7 weeks respectively.

Table 1. Participants of the 15 Regional Centers and Core Center of the JECS.

\begin{tabular}{ccc}
\hline Unit Center & $\boldsymbol{n}$ & $\mathbf{\%}$ \\
\hline Hokkaido & 7709 & 7.9 \\
Miyagi & 8775 & 9.0 \\
Fukushima & 12,820 & 13.2 \\
Chiba & 5461 & 5.6 \\
Kanagawa & 6288 & 6.5 \\
Koshin & 7020 & 7.2 \\
Toyama & 5326 & 5.5 \\
Aichi & 5451 & 5.6 \\
Kyoto & 3082 & 3.2 \\
Osaka & 7735 & 7.9 \\
Hyogo & 4951 & 5.1 \\
Tottori & 3007 & 3.1 \\
Kochi & 6817 & 7.0 \\
Fukuoka & 7403 & 7.6 \\
South Kyusyu and Okinawa & 5619 & 5.8 \\
\hline
\end{tabular}


Table 2. Characteristics of study subjects $(n=97,464)$.

\begin{tabular}{|c|c|c|c|}
\hline & & $n$ & $\%$ \\
\hline \multirow[t]{2}{*}{ Gestation (weeks) of In-T1 } & Median(IQR) & \multicolumn{2}{|c|}{$15.7(12.3-22.1)$} \\
\hline & No response & 530 & 0.5 \\
\hline \multirow[t]{2}{*}{ Gestation (weeks) of In-T2 } & Median(IQR) & \multicolumn{2}{|c|}{$27.6(25.3-31.7)$} \\
\hline & No response & 526 & 0.5 \\
\hline \multirow[t]{3}{*}{ Gestation (weeks) of M-T1 } & Mean +/-SD & \multirow{2}{*}{\multicolumn{2}{|c|}{$\begin{array}{c}16.8+/-7.4 \\
15.4(12.4-19.4)\end{array}$}} \\
\hline & Median(IQR) & & \\
\hline & No response & 859 & 0.9 \\
\hline \multirow[t]{3}{*}{ Gestation (weeks) of M-T2 } & Mean +/-SD & \\
\hline & Median(IQR) & \multicolumn{2}{|c|}{$27.7(25.3-30.4)$} \\
\hline & No response & 913 & 0.9 \\
\hline \multirow[t]{5}{*}{ Age } & Mean +/-SD & \multicolumn{2}{|c|}{$30.8+/-5.0$} \\
\hline & $<30$ years & 39,460 & 40.5 \\
\hline & 30-34 years & 33,918 & 34.8 \\
\hline & $\geq 35$ years & 23,683 & 24.3 \\
\hline & No response & 403 & 0.4 \\
\hline \multirow[t]{3}{*}{ Marital status } & Married & 92,478 & 94.9 \\
\hline & Single/divorced/widowed & 4183 & 4.3 \\
\hline & No response & 803 & 0.8 \\
\hline \multirow[t]{4}{*}{ Education } & Junior high/high school & 35,109 & 36.0 \\
\hline & Technical/junior college & 40,517 & 41.6 \\
\hline & University/graduate school & 20,816 & 21.4 \\
\hline & No response & 1022 & 1.1 \\
\hline \multirow[t]{4}{*}{ Family income } & $<4,000,000$ yen & 36,280 & 37.2 \\
\hline & $\geq 4,000,000$ and $<6,000,000$ yen & 29,788 & 30.6 \\
\hline & $\geq 6,000,000$ yen & 24,025 & 24.7 \\
\hline & No response & 7371 & 7.6 \\
\hline \multirow[t]{4}{*}{ Body mass index } & $<18.5 \mathrm{~kg} / \mathrm{m}^{2}$ & 15,595 & 16.0 \\
\hline & $\geq 18.5$ and $<25 \mathrm{~kg} / \mathrm{m}^{2}$ & 70,483 & 72.3 \\
\hline & $\geq 25 \mathrm{~kg} / \mathrm{m}^{2}$ & 10,301 & 10.6 \\
\hline & No response & 1085 & 1.1 \\
\hline \multirow[t]{4}{*}{ Smoking } & Nonsmokers & 56,115 & 57.6 \\
\hline & Ever smokers & 35,632 & 36.6 \\
\hline & Current smokers & 4615 & 4.7 \\
\hline & No response & 1102 & 1.1 \\
\hline \multirow[t]{4}{*}{ Alcohol consumption } & Nondrinkers & 33,461 & 34.3 \\
\hline & Ever drinkers & 53,612 & 55.0 \\
\hline & Current drinkers & 9570 & 9.8 \\
\hline & No response & 821 & 0.8 \\
\hline \multirow[t]{3}{*}{ Parity } & Primipara & 38,397 & 39.4 \\
\hline & Multipara & 56,786 & 58.3 \\
\hline & No response & 2281 & 2.3 \\
\hline \multirow[t]{3}{*}{ Fertility treatment } & Yes & 6463 & 6.6 \\
\hline & No & 90,595 & 93.0 \\
\hline & No response & 406 & 0.4 \\
\hline \multirow[t]{3}{*}{ History of spontaneous abortion } & Yes & 18,410 & 18.9 \\
\hline & No & 77,476 & 79.5 \\
\hline & No response & 1578 & 1.6 \\
\hline
\end{tabular}


Table 2. Cont

\begin{tabular}{|c|c|c|c|}
\hline & & $n$ & $\%$ \\
\hline \multirow[t]{3}{*}{ History of a mental health disorder } & No & 89,531 & 91.9 \\
\hline & Yes & 7551 & 7.8 \\
\hline & No response & 382 & 0.4 \\
\hline \multirow[t]{3}{*}{ Hypertension } & No & 95,766 & 98.3 \\
\hline & Yes & 1189 & 1.2 \\
\hline & No response & 509 & 0.5 \\
\hline \multirow[t]{3}{*}{ Diabetes } & No & 95,909 & 98.4 \\
\hline & Yes & 1046 & 1.1 \\
\hline & No response & 509 & 0.5 \\
\hline \multirow[t]{3}{*}{ Mental health disorder } & No & 96,183 & 98.7 \\
\hline & Yes & 772 & 0.8 \\
\hline & No response & 509 & 0.5 \\
\hline \multirow[t]{3}{*}{ Other pregnancy complication } & No & 84,305 & 86.5 \\
\hline & Yes & 12,650 & 13.0 \\
\hline & No response & 509 & 0.5 \\
\hline \multirow[t]{4}{*}{ Hypertensive disorders of pregnancy } & No & 93,896 & 96.3 \\
\hline & Mild & 2114 & 2.2 \\
\hline & Severe & 945 & 1.0 \\
\hline & No response & 509 & 0.5 \\
\hline \multirow[t]{3}{*}{ Gestational diabetes } & No & 94,302 & 96.8 \\
\hline & Yes & 2653 & 2.7 \\
\hline & No response & 509 & 0.5 \\
\hline \multirow[t]{3}{*}{ Other obstetric labor complication } & No & 54,648 & 56.1 \\
\hline & Yes & 42,307 & 43.4 \\
\hline & No response & 509 & 0.5 \\
\hline
\end{tabular}

In-T1: Interview within the maternal first trimester; In-T2: Interview within the second or third trimester; M-T1: Questionnaire within the maternal first trimester; M-T2: Questionnaire within the second or third trimester; IQR: Interquartile range; SD: Standard deviation.

The drugs most commonly used by the women are presented in Table 3. The following drugs and supplements (five upstream items) were frequently used during the 12 months before pregnancy diagnosis: (1) commercially available antipyretics, analgesics, and/or medicine for treating common colds (34.68\%), (2) antipyretics, analgesics, and/or medicine for treating common cold prescribed in hospitals (29.82\%), (3) antimicrobial drugs (14.02\%), (4) anti-allergy drugs (12.53\%), and (5) Chinese herbal medicines $(8.61 \%)$. 
Table 3. Drug use before and during pregnancy in Japan from 2011 to 2014 ( $n=97,464$ ).

\begin{tabular}{|c|c|c|c|c|c|c|c|}
\hline & & \multicolumn{2}{|c|}{$\begin{array}{c}\text { Before Pregnancy } \\
\text { Diagnosis }\end{array}$} & \multicolumn{2}{|c|}{$\begin{array}{l}\text { Before Week } 12 \text { of } \\
\text { Pregnancy }\end{array}$} & \multicolumn{2}{|c|}{$\begin{array}{l}\text { After Week } 12 \\
\text { of Pregnancy }\end{array}$} \\
\hline & & $n$ & $\%$ & $n$ & $\%$ & $n$ & $\%$ \\
\hline \multirow{4}{*}{ Antibacterial, Antiviral, Antifungal, Carcinostatic drugs } & Antimicrobial & 13,668 & 14.02 & 3223 & 3.31 & 8415 & 8.63 \\
\hline & Antiviral & 3749 & 3.85 & 1194 & 1.23 & 1521 & 1.56 \\
\hline & Antifungal & 936 & 0.96 & 1112 & 1.14 & 1904 & 1.95 \\
\hline & Carcinostatic & 628 & 0.64 & 503 & 0.52 & 65 & 0.07 \\
\hline \multirow[t]{2}{*}{ Corticosteroids } & Corticosteroids: oral administration, inhalation, infusion & 3008 & 3.09 & 1120 & 1.15 & 1660 & 1.70 \\
\hline & Corticosteroids: external use, enema & 5415 & 5.56 & 2756 & 2.83 & 4283 & 4.39 \\
\hline \multirow{3}{*}{ Antipyreic, Analgesic drugs } & Antipyretic, Analgesic, Medicine for common cold: prescription & 29,064 & 29.82 & 7498 & 7.82 & 12,982 & 13.32 \\
\hline & Antipyretic, Analgesic, Medicine for common cold: over the counter & 33,799 & 34.68 & 3035 & 3.16 & 1162 & 1.19 \\
\hline & Poultice which the analgesic is included in & 4352 & 4.47 & 926 & 0.97 & 1711 & 1.76 \\
\hline \multirow{3}{*}{ Antirheumatic drugs } & Immunosuppressant, Immunoregulation & 650 & 0.67 & 470 & 0.48 & 144 & 0.15 \\
\hline & Infliximab, Etanercept & 42 & 0.04 & 20 & 0.02 & 21 & 0.02 \\
\hline & Antirheumatic drug unidentified in detail & 14 & 0.01 & 4 & 0.00 & 4 & 0.00 \\
\hline Antiallergy drugs & $\begin{array}{l}\text { Antiallergic drug } \\
\text { (oral administration, inhalation, nasal drip, tape, Antihistaminic) }\end{array}$ & 12,213 & 12.53 & 2688 & 2.76 & 5389 & 5.53 \\
\hline \multirow[t]{5}{*}{ Respiratory drugs } & $\beta$ stimulative (oral administration, inhalation) & 528 & 0.54 & 286 & 0.29 & 541 & 0.56 \\
\hline & Nontypable inhalant & 144 & 0.15 & 51 & 0.05 & 77 & 0.08 \\
\hline & Antitussive, Expectorant & 4711 & 4.83 & 1362 & 1.40 & 4131 & 4.24 \\
\hline & Theophylline & 346 & 0.36 & 88 & 0.09 & 189 & 0.19 \\
\hline & Other respiratory drug & 207 & 0.21 & 89 & 0.09 & 181 & 0.19 \\
\hline \multirow[t]{4}{*}{ Antidiabetic drugs, Antihyperlipidemic drugs } & Insulin preparation & 100 & 0.10 & 163 & 0.17 & 289 & 0.30 \\
\hline & Hypoglycemic tablet & 207 & 0.21 & 96 & 0.10 & 35 & 0.04 \\
\hline & Antihyperlipidemic & 79 & 0.08 & 27 & 0.03 & 26 & 0.03 \\
\hline & Antigout & 9 & 0.01 & 2 & 0.00 & 2 & 0.00 \\
\hline \multirow[t]{3}{*}{ Hormone-related drugs } & Thyroid hormone preparation/levothyroxine sodium & 642 & 0.66 & 640 & 0.66 & 710 & 0.73 \\
\hline & Antithyroid/Thiamazole & 360 & 0.37 & 309 & 0.32 & 311 & 0.32 \\
\hline & Other hormone drugs & 2245 & 2.30 & 966 & 0.99 & 340 & 0.35 \\
\hline \multirow{2}{*}{ Blood-related drugs } & Iron preparartion & 1243 & 1.28 & 1670 & 1.71 & 11,736 & 12.04 \\
\hline & Other blood-related & 1030 & 1.06 & 2181 & 2.24 & 2040 & 2.09 \\
\hline \multirow[t]{5}{*}{ Cardiovasucular drugs } & Antihypertensive (including diuretic) & 269 & 0.28 & 145 & 0.15 & 291 & 0.30 \\
\hline & Pressor & 32 & 0.03 & 8 & 0.01 & 18 & 0.02 \\
\hline & Antiarrhythmic, Antianginal & 51 & 0.05 & 49 & 0.05 & 68 & 0.07 \\
\hline & Heart failure therapeutic & 3 & 0.00 & 2 & 0.00 & 3 & 0.00 \\
\hline & Other caridiovasucular drugs & 181 & 0.19 & 142 & 0.15 & 167 & 0.17 \\
\hline
\end{tabular}


Table 3. Cont

\begin{tabular}{|c|c|c|c|c|c|c|c|}
\hline & & \multicolumn{2}{|c|}{$\begin{array}{c}\text { Before Pregnancy } \\
\text { Diagnosis }\end{array}$} & \multicolumn{2}{|c|}{$\begin{array}{c}\text { Before Week } 12 \text { of } \\
\text { Pregnancy }\end{array}$} & \multicolumn{2}{|c|}{$\begin{array}{l}\text { After Week } 12 \\
\text { of Pregnancy }\end{array}$} \\
\hline & & $n$ & $\%$ & $n$ & $\%$ & $n$ & $\%$ \\
\hline \multirow[t]{3}{*}{ Gastrointestinal drugs } & Antiulcer (Proton pump inhibitor, $\mathrm{H} 2$ blocker) & 1397 & 1.43 & 345 & 0.35 & 686 & 0.70 \\
\hline & General gastrointestinal agents & 8107 & 8.32 & 2777 & 2.85 & 5036 & 5.17 \\
\hline & Other gastrointestinal agents & 2325 & 2.39 & 1416 & 1.45 & 2176 & 2.23 \\
\hline \multirow[t]{9}{*}{ Psychoactive drugs } & Selective serotonin reuptake inhibitors (SSRI) & 518 & 0.53 & 173 & 0.18 & 149 & 0.15 \\
\hline & Antidepressant drug except the SSRI & 265 & 0.27 & 91 & 0.09 & 79 & 0.08 \\
\hline & Antianxiety & 992 & 1.02 & 326 & 0.33 & 372 & 0.38 \\
\hline & Sleeping pill & 946 & 0.97 & 228 & 0.23 & 238 & 0.24 \\
\hline & Antipsychotic & 233 & 0.24 & 104 & 0.11 & 119 & 0.12 \\
\hline & Valproic acid & 180 & 0.18 & 66 & 0.07 & 68 & 0.07 \\
\hline & Antiepileptic except the above & 142 & 0.15 & 117 & 0.12 & 133 & 0.14 \\
\hline & Lithium carbonate & 30 & 0.03 & 3 & 0.00 & 4 & 0.00 \\
\hline & Other psychoactive drugs & 116 & 0.12 & 32 & 0.03 & 33 & 0.03 \\
\hline \multirow[t]{4}{*}{ Perinatal drugs } & Utero relaxants & 522 & 0.54 & 4982 & 5.11 & 14,822 & 15.21 \\
\hline & Utero-tonic & 795 & 0.82 & 188 & 0.19 & 279 & 0.29 \\
\hline & Ovulation inducing & 3846 & 3.95 & 277 & 0.28 & 22 & 0.02 \\
\hline & Other perinatal related drugs & 2420 & 2.48 & 2672 & 2.74 & 1964 & 2.02 \\
\hline \multirow[t]{10}{*}{ Other drugs } & Anesthetic, pain block injection & 932 & 0.96 & 112 & 0.11 & 447 & 0.46 \\
\hline & Chinese herbal medicines & 8389 & 8.61 & 5865 & 6.02 & 9175 & 9.41 \\
\hline & External application (non-identified contents) & 4905 & 5.03 & 1972 & 2.02 & 3966 & 4.07 \\
\hline & Injection, Drip infusion (non-identified contents) & 1460 & 1.50 & 1043 & 1.07 & 942 & 0.97 \\
\hline & Bone \& Calcium metabolism & 93 & 0.10 & 95 & 0.10 & 126 & 0.13 \\
\hline & Antimigraine headache & 308 & 0.32 & 60 & 0.06 & 87 & 0.09 \\
\hline & Muscle relaxant & 269 & 0.28 & 23 & 0.02 & 21 & 0.02 \\
\hline & Antiemetic drug & 985 & 1.01 & 1802 & 1.85 & 1316 & 1.35 \\
\hline & AntiParkinson & 112 & 0.11 & 38 & 0.04 & 12 & 0.01 \\
\hline & Hemorrhoids & 297 & 0.30 & 377 & 0.39 & 1076 & 1.10 \\
\hline \multirow[t]{9}{*}{ Supplements, vitamins/minerals } & Folic acid & 6810 & 6.99 & 28,153 & 28.89 & 25,494 & 26.16 \\
\hline & Vitamin A & 122 & 0.13 & 70 & 0.07 & 72 & 0.07 \\
\hline & Vitamin B & 2648 & 2.72 & 2282 & 2.34 & 2894 & 2.97 \\
\hline & Vitamin C & 2794 & 2.87 & 1536 & 1.58 & 1793 & 1.84 \\
\hline & Vitamin D & 131 & 0.13 & 111 & 0.11 & 148 & 0.15 \\
\hline & Vitamin E & 636 & 0.65 & 277 & 0.28 & 267 & 0.27 \\
\hline & Mineralas & 1760 & 1.81 & 4797 & 4.92 & 6751 & 6.93 \\
\hline & Multi vitamins supplement & 3766 & 3.86 & 2956 & 3.03 & 3059 & 3.14 \\
\hline & Total supplement & 2620 & 2.69 & 2680 & 2.75 & 3380 & 3.47 \\
\hline
\end{tabular}


Table 3. Cont.

\begin{tabular}{|c|c|c|c|c|c|c|c|}
\hline & & \multicolumn{2}{|c|}{$\begin{array}{c}\text { Before Pregnancy } \\
\text { Diagnosis }\end{array}$} & \multicolumn{2}{|c|}{$\begin{array}{c}\text { Before Week } 12 \text { of } \\
\text { Pregnancy }\end{array}$} & \multicolumn{2}{|c|}{$\begin{array}{l}\text { After Week } 12 \\
\text { of Pregnancy }\end{array}$} \\
\hline & & $n$ & $\%$ & $n$ & $\%$ & $n$ & $\%$ \\
\hline \multirow[t]{6}{*}{ Illegal drugs } & Marijuana & 2 & 0.00 & 1 & 0.00 & 3 & 0.00 \\
\hline & Psychostimulant & 1 & 0.00 & 0 & 0.00 & 2 & 0.00 \\
\hline & Ecstasy & 0 & 0.00 & 0 & 0.00 & 1 & 0.00 \\
\hline & Thinner & 1 & 0.00 & 0 & 0.00 & 0 & 0.00 \\
\hline & Toluene & 2 & 0.00 & 0 & 0.00 & 0 & 0.00 \\
\hline & Other illegal drugs & 2 & 0.00 & 1 & 0.00 & 0 & 0.00 \\
\hline \multicolumn{2}{|l|}{ Vaccines } & 1431 & 1.47 & 318 & 0.33 & 897 & 0.92 \\
\hline \multicolumn{2}{|c|}{ Drugs not included in the list mentioned above } & 5064 & 5.20 & 3011 & 3.09 & 5272 & 5.41 \\
\hline \multicolumn{2}{|c|}{ Forgot the drug name } & 1342 & 1.38 & 486 & 0.50 & 607 & 0.62 \\
\hline
\end{tabular}

Before diagnosis of pregnancy: Drug use during the 12 months before diagnosis of pregnancy, Before week 12 of pregnancy: Drug use between the time from diagnosis of pregnancy until week 12 of pregnancy, After week 12 of pregnancy: Drug use from week 12 of pregnancy until the "In-T1" or "In-T2" interview. 
The following drugs and supplements (five upstream items) were frequently used from the time of pregnancy diagnosis until week 12 of pregnancy: (1) folic acid $(28.89 \%)$, (2) antipyretics, analgesics, and/or medicine for treating common cold prescribed in hospitals (7.76\%), (3) Chinese herbal medicines $(6.02 \%),(4)$ uterine relaxants $(5.11 \%)$, and (5) minerals $(4.92 \%)$.

The following drugs and supplements (five upstream items) were frequently used from week 12 of pregnancy until the time of the "In-T2" interview: (1) folic acid (26.16\%), (2) uterine relaxants $(15.21 \%)$, (3) antipyretics, analgesics, and/or medicine for treating common cold prescribed in hospitals $(13.32 \%)$, (4) iron preparations (12.04\%), and (5) Chinese herbal medicines $(9.41 \%)$.

Drug combinations are shown in Table 4 . The percentages of pregnant women that took one or more drugs before diagnosis of pregnancy, between the time of diagnosis of pregnancy until week 12 of pregnancy, and after week 12 of pregnancy, were $78.41 \%, 57.07 \%$, and $68.84 \%$, respectively. A maximum of 10 drugs were combined for the before-pregnancy diagnosis, 11 from the time period between pregnancy diagnosis until week 12 of pregnancy, and 14 for the time period after week 12 of pregnancy.

Table 4. Percentage of pregnant women taking more than one medication including supplements, folic acid, and other vitamins and minerals $(n=97,464)$.

\begin{tabular}{cccc}
\hline \multirow{2}{*}{ Number of Items } & $\begin{array}{c}\text { Before Pregnancy } \\
\text { Diagnosis }\end{array}$ & $\begin{array}{c}\text { Before Week 12 } \\
\text { of Pregnancy }\end{array}$ & $\begin{array}{c}\text { After Week 12 } \\
\text { of Pregnancy }\end{array}$ \\
\cline { 2 - 4 } & $\mathbf{\%}$ & $\mathbf{\%}$ & \% \\
\hline 0 & 21.59 & 42.93 & 31.16 \\
1 & 25.54 & 27.61 & 25.51 \\
2 & 20.06 & 15.46 & 18.49 \\
3 & 19.34 & 9.75 & 5.30 \\
4 & 5.14 & 2.60 & 2.57 \\
5 & 3.32 & 0.97 & 1.39 \\
6 & 2.56 & 0.43 & 0.69 \\
7 & 1.51 & 0.17 & 0.40 \\
8 & 0.69 & 0.06 & 0.19 \\
9 & 0.24 & 0.02 & 0.08 \\
10 & 0.02 & 0.01 & 0.03 \\
11 & - & 0.003 & 0.01 \\
12 & - & - & 0.005 \\
13 & - & - & 0.002 \\
14 & - & - & 68.84 \\
\hline 1 & 78.41 & 57.07 & \\
\hline
\end{tabular}

We analyzed the data, excluding data pertaining to iron supplements, folic acid, and other vitamins and minerals (Table 5). The percentages of pregnant women who had used one or more drugs before diagnosis of pregnancy, from pregnancy diagnosis until week 12 of pregnancy, and after week 12 of pregnancy, were $75.33 \%, 36.02 \%$, and $51.72 \%$, respectively. A maximum of 10 drugs were combined for the before-pregnancy diagnosis, 10 for the time period between pregnancy diagnosis until Week 12 of pregnancy, and 12 for the time period after Week 12 of pregnancy. 
Table 5. Percentage of pregnant women taking more than one medication excluding supplements, folic acid, and other vitamins and minerals $(n=97,464)$.

\begin{tabular}{cccc}
\hline \multirow{2}{*}{ Number of Items } & $\begin{array}{c}\text { Before Pregnancy } \\
\text { Diagnosis }\end{array}$ & $\begin{array}{c}\text { Before Week 12 } \\
\text { of Pregnancy }\end{array}$ & $\begin{array}{c}\text { After Week 12 } \\
\text { of Pregnancy }\end{array}$ \\
\cline { 2 - 4 } & $\mathbf{\%}$ & $\mathbf{\%}$ & $\mathbf{\%}$ \\
\hline 0 & 24.67 & 63.98 & 48.28 \\
1 & 28.46 & 20.54 & 25.22 \\
2 & 20.71 & 9.03 & 13.65 \\
3 & 15.39 & 4.10 & 7.52 \\
4 & 4.50 & 1.39 & 2.71 \\
5 & 2.75 & 0.58 & 1.32 \\
6 & 1.80 & 0.26 & 0.68 \\
7 & 1.08 & 0.08 & 0.35 \\
8 & 0.50 & 0.03 & 0.17 \\
9 & 0.14 & 0.01 & 0.07 \\
10 & 0.01 & 0.005 & 0.03 \\
11 & - & - & 0.01 \\
12 & - & - & 0.003 \\
$\geq 1$ & 75.33 & 36.02 & 51.72 \\
\hline
\end{tabular}

\section{Discussion}

To the best of our knowledge, this study is the first large-scale nationwide investigation on drug use during pregnancy in Japan. Of 101,490 records in the data set, we analyzed the records of 97,464.

The percentage of pregnant women who had used one or more drugs from the time of pregnancy diagnosis until week 12 of pregnancy was $57.07 \%$. This finding was lower than the percentages reported in studies on pregnant women who had used drugs during the first trimester in Germany (69.7\%) [9] and China (75.9\%) [22], and higher than the figures reported in studies on pregnant women who had used drugs during the first trimester in Italy $(30.7 \%, 41.0 \%)$ [10,11], The Netherlands (43.6\%) [12], and Norway (32.8\%) [14]. When we excluded iron, folic acid, and other vitamin and mineral supplements from our analysis, the percentage of drug usage from the time of pregnancy diagnosis until Week 12 of pregnancy was lowered to $36.02 \%$. The prevalence of pregnant women who had used drugs during the first trimester in this cohort was similar to that which was reported in studies conducted in the United States (39.0\%) [15], lower than that reported in studies conducted in Germany (53.6\%) [9] and China (47.7\%) [22], and higher than that which was reported in those conducted in Denmark $(21.6 \%)$ [4]. In comparison to the findings of studies conducted in other countries, the percentage of pregnant women who had used drugs during the early pregnancy period in our cohort was moderate.

The following drugs and supplements (three upstream items) were frequently used from the time of diagnosis of pregnancy until week 12 of pregnancy: (1) folic acid $(28.89 \%),(2)$ antipyretics, analgesics, and/or medicine for treating common cold prescribed in hospitals (7.76\%), and (3) Chinese herbal medicines $(6.02 \%)$. The following drugs and supplements (three upstream items) were frequently used from week 12 of pregnancy until the time of the "In-T2" interview (the median gestation was 27.6 weeks): (1) folic acid (26.16\%), (2) uterine relaxants (15.21\%), (3) antipyretics, analgesics, and/or medicines for treating the common cold as prescribed in hospitals $(13.32 \%)$.

During the first trimester, the most common drugs dispensed in other countries were as follows. Germany: alimentary tract and metabolism, 45\% [9]; Italy: hematological, 15.2\% [10]; The Netherlands: folic acid, 8.4\% [13] and folic acid and derivatives, 6.1\% [12]; Norway: antibacterials for systemic use, 9.5\% [14]; Denmark: penicillin, 16\% [6]; the United States: anti-infectives, 18.3\% [15]; China: folic acid, $65 \%$ [22].

During the second trimester, the most common drugs dispensed in other countries were as follows. Germany: alimentary tract and metabolism, 46\% [9]; Italy: hematological, 30.8\% [10]; The Netherlands: 
iron preparations, 30.6\% [13] and 21.0\% [12]; Norway: antibacterials for systemic use, $12.0 \%$ [14]; Denmark: penicillin, 18\% [6]; the United States: anti-infectives, 17.2\% [15].

Regarding folic acid ingestion, $6.99 \%$ of the pregnant women in our study had consumed folic acid before diagnosis of pregnancy. From the time of diagnosis of pregnancy until week 12 of pregnancy, and from week 12 of pregnancy until the time of the "In-T2" interview, the percentages were $28.89 \%$ and $26.16 \%$, respectively. These values before and after pregnancy diagnosis were markedly lower than those reported in the studies conducted in other countries [27]. This indicates that Japanese women of childbearing age should be informed about the need for folic acid intake before pregnancy, to prevent neural tube defects.

The percentage of pregnant women who had received iron preparations from the time of diagnosis of pregnancy until week 12 of pregnancy was $1.71 \%$; this increased after week 12 to $12.04 \%$. This trend is similar but lower than the results reported in studies conducted in Germany (10\%, 30\%, 40\%) [9] and The Netherlands $(7.7 \%, 30.6 \%, 44.6 \%)$ [13], and $5.2 \%, 21.0 \%$, and $31.5 \%$ [12], in a cohort of women who had used drugs during the first, second, and third trimesters respectively. We presumed that the percentage of pregnant women taking iron supplements in Japan was lower than that in Germany and The Netherlands because the frequency of anemia in Japanese pregnant women is low, and treatment guidelines for the use of iron supplements vary. Further research is probably required.

The percentages of pregnant women who had taken Chinese herbal medicines during the time period from the time of diagnosis of pregnancy until week 12 of pregnancy, and after week 12 of pregnancy, were $6.02 \%$ and $9.41 \%$; the percentages were high after diagnosis of pregnancy. However, in this survey, the term "Chinese herbal medicines" included all types of preparations, and thus the findings must be carefully interpreted. However, these percentages were similar to the level of use in China during the first trimester (10.1\%) [22]. Chinese herbal medicine contains a large number of ingredients, and there is limited information concerning its safety during pregnancy. Safety information must be made available in the future concerning the use of these preparations during pregnancy.

The percentage of pregnant women who had received uterine relaxants during the time period from the time of diagnosis of pregnancy until week 12 of pregnancy was $5.11 \%$; this increased after week 12 of pregnancy to $15.21 \%$. This trend was similar to that reported in the studies conducted in Italy on tocolytic drug use during the first (5.5\%), second (10.4\%), and third (10.9\%) trimesters [10].

The percentages of pregnant women who had used one or more drugs, excluding those pertaining to iron supplements, folic acid, and other vitamins and minerals, during the time period between the time of diagnosis of pregnancy until week 12 of pregnancy, was $36.02 \%$. A maximum of 10 drugs were combined for the time period between diagnosis of pregnancy until week 12 of pregnancy. The percentage of pregnant women who had used four or more drugs between the time period from the time of diagnosis of pregnancy until week 12 of pregnancy was $2.35 \%$. This finding was similar to that reported in the National Birth Defects Prevention Study $(2.2 \%)$, and lower than that reported in the Slone Epidemiology Center Birth Defects Study (7.5\%) conducted in the United States [24].

\section{Limitations}

The subjects of this survey were limited to only pregnant women that participated in JECS voluntarily. Thus, a number of cooperative and health conscious pregnant women likely participated in the survey. Therefore, there is some selection bias here. Furthermore, the self-reporting setup may have resulted in some cases in which drug use was not reported. No validation studies were carried out to assess the accuracy of the reports of medications. Therefore, these findings must be carefully interpreted.

The "exposure time-period" from after week 12 until the "In-T2" interview was not the same for each participant, as seen from the median (IQR) on gestation of In-T2 in Table 2, and hence, drug use data after week 12 of pregnancy may not have been complete, since some participants may have been interviewed late in the second trimester, or early in the third trimester, and thus, their drug use in the third trimester would not have been collected, or may have been underestimated. Therefore, 
in general, data on drug use after Week 12 of pregnancy was likely to have been underestimated in this study.

Some drug types in the dataset were not subclassified (Appendix C). ATC code-based drug and risk classification was not conducted, unlike the surveys conducted in Europe and the United States; it may be difficult to compare our results with those of other surveys because data sources and collection methods differed.

We could not distinguish between prescription drug use and over-the-counter drug use, because our questionnaire did not completely distinguish between prescription drug use and over-the-counter drug use.

There has been no prior drug-related study based on a large-scale birth cohort survey in Japan, and these data are a valuable starting point for pregnancy management in Japan.

\section{Conclusions}

The analysis of a large nationwide cohort study showed that a high percentage of Japanese pregnant women were taking medicinal drugs, even when iron, folic acid, and other supplements were excluded. Further research is required to elucidate the relationship between drug use during pregnancy and birth defects in Japan.

Acknowledgments: Members of the Japan Environment and Children's Study (JECS) as of 2016 (principal investigator, Toshihiro Kawamoto): Hirohisa Saito (National Center for Child Health and Development, Tokyo, Japan), Reiko Kishi (Hokkaido University, Sapporo, Japan), Nobuo Yaegashi (Tohoku University, Sendai, Japan), Koichi Hashimoto (Fukushima Medical University, Fukushima, Japan), Chisato Mori (Chiba University, Chiba, Japan), Shuichi Ito (Yokohama City University, Yokohama, Japan), Zentaro Yamagata (University of Yamanashi, Chuo, Japan), Hidekuni Inadera (University of Toyama, Toyama, Japan), Michihiro Kamijima (Nagoya City University, Nagoya, Japan), Toshio Heike (Kyoto University, Kyoto, Japan), Hiroyasu Iso (Osaka University, Suita, Japan), Masayuki Shima (Hyogo College of Medicine, Nishinomiya, Japan), Yasuaki Kawai (Tottori University, Yonago, Japan), Narufumi Suganuma (Kochi University, Nankoku, Japan), Koichi Kusuhara (University of Occupational and Environmental Health, Kitakyushu, Japan), Takahiko Katoh (Kumamoto University, Kumamoto, Japan). Funding: The Japan Environment and Children's Study was funded by the Ministry of the Environment, Japan. The findings and conclusions of this article are solely the responsibility of the authors and do not represent the official views of the above government. This research was also supported by Research Promotion and Practical Use for Women's Health, AMED.

Author Contributions: H.N., T.O., T.N., N.M., S.K., and N.Y. conceived and designed the experiments; H.N., T.O., T.N., H.M., M.I., S.M., K.S., I.N., performed the experiments; H.N., T.O., and T.N. analyzed the data; H.M., M.I., S.M., K.S., T.N., I.F., T.A., K.N., N.M., S.K., and N.Y. contributed reagents/materials/analysis tools; H.N., T.O., and T.N. wrote the paper." Authorship must be limited to those who have contributed substantially to the work reported.

Conflicts of Interest: The authors declare no conflict of interest. 


\section{Appendix A}

\section{This questionnaire will be filled in by the JECS survey staff.}

Question 1: Have you taken any medication since you became pregnant? Have you been administered intravenous drips or injections etc., or prescribed any medication for external use?

$$
\square \text { Yes }
$$

$\square$ No

Question 2: Following the interviewer's instruction, please list any particular drugs you have taken since you became pregnant. Amount of drug taken is not relevant. Please do not include enemas and medication for diarrhea and constipation here. Please include any drugs and supplements.

(1) Period from the time of finding out pregnancy to the $12^{\text {th }}$ week of pregnancy

* If you have already answered these questions in the early pregnancy questionnaire, you can skip (1).

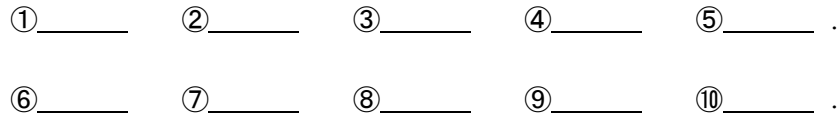

(2) Period from the $12^{\text {th }}$ week of pregnancy to date

(6)
(2)

(7)
(3)

(8)
(4)

(9)
(5)

(10)

Figure A1. Medication questionnaire (In-T1).

\section{Appendix B}

This questionnaire will be filled in by the JECS survey staff.

Question 1: Have you taken any medication in the past 12 months? Or, have you been administered intravenous drips or injections etc.?
$\square$ Yes
$\square$ No

Question 2: (If you answered "yes" to Question 1) Following the interviewer's instruction, please list any particular drugs you have taken in the past 12 months.

(1) Period between 12 months ago and the time when you found out about pregnancy
(1)
(2)
(3)
(4)
(5)
(6)
(7)
(8)
(9)
(10)

(2) Period from the time of finding out pregnancy to the $12^{\text {th }}$ week of pregnancy
(1)
(2)
(3)
(4)
(5)
(6)
(7)
(8)
(9)
(10)

(3) Period from the $12^{\text {th }}$ week of pregnancy to date
(1)
(3)
(4)
(5)
(6)
(7)
(8)
(9)
(10)

Figure A2. Medication questionnaire (In-T2). 


\section{Appendix C}

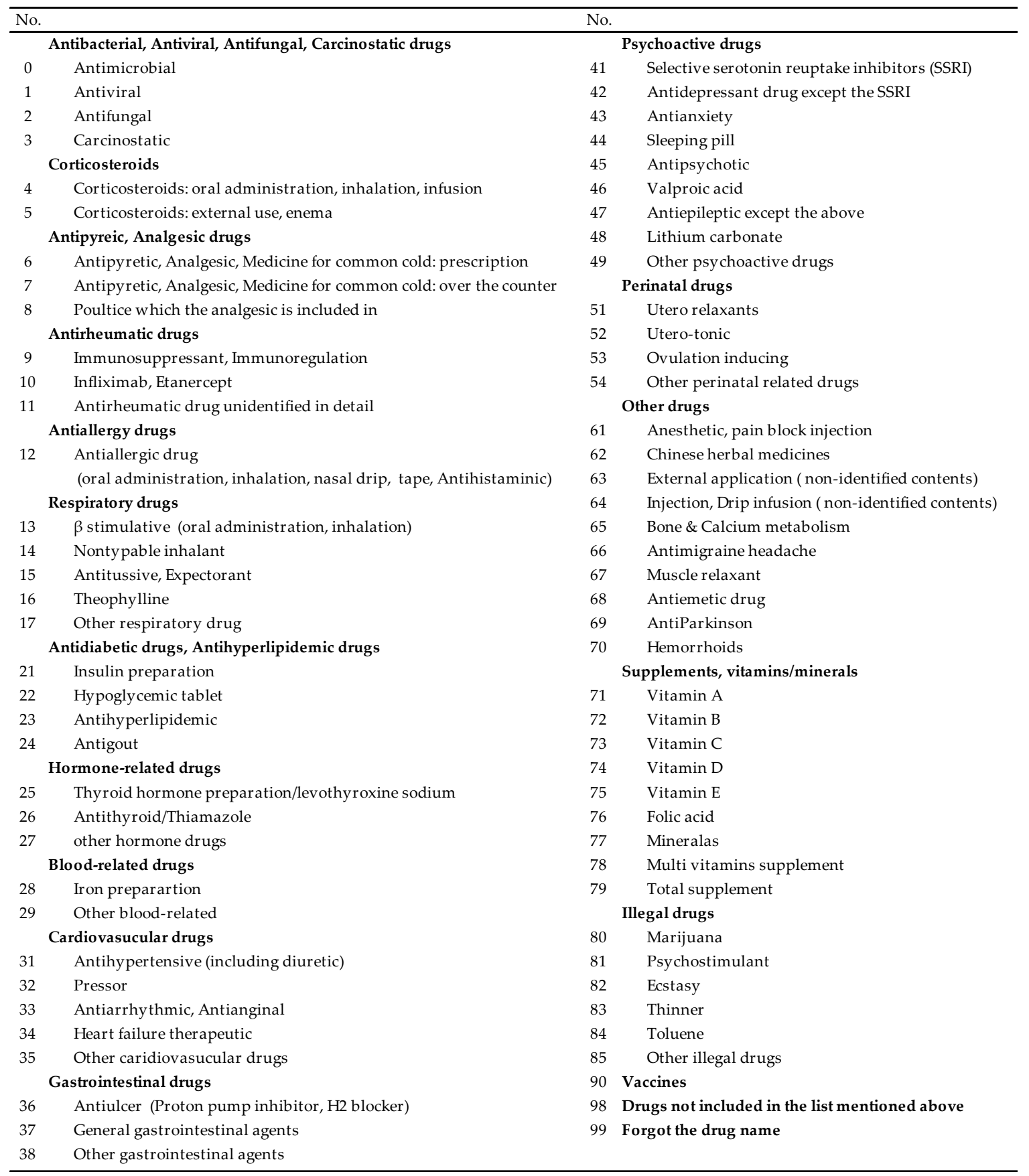

Figure A3. Medication list.

\section{References}

1. Källén, B.A.J. Methodological issues in the epidemiological study of the teratogenicity of drugs. Congenit. Anom. 2005, 45, 44-51. [CrossRef] [PubMed]

2. Kulaga, S.; Zagarzadeh, A.; Berard, A. Prescriptions filled during pregnancy for drugs with the potential of fetal harm. BJOG 2009, 116, 1788-1795. [CrossRef] [PubMed]

3. Malm, H.; Martikainen, J.; Klaukka, T.; Neuvonen, P.J. Prescription drugs during pregnancy and lactation-A Finnish register-based study. Eur. J. Clin. Pharmacol. 2003, 59, 127-133. [CrossRef] [PubMed] 
4. $\quad$ Olesen, C.; Sorensen, H.T.; de Jong-van den Berg, L.; Olsen, J.; Steffensen, F.H.; Grp, E. Prescribing during pregnancy and lactation with reference to the Swedish classification system-A population-based study among Danish women. Acta Obstet. Gynecol. Scand. 1999, 78, 686-692. [CrossRef] [PubMed]

5. Olesen, C.; Steffensen, F.; Nielsen, G.; de Jong-van den Berg, L.; Olsen, J.; Sorensen, H. Drug use in first pregnancy and lactation: A population-based survey among Danish women. Eur. J. Clin. Pharmacol. 1999, 55, 139-144. [CrossRef] [PubMed]

6. Olesen, C.; Thrane, N.; Henriksen, T.; Ehrenstein, V.; Olsen, J. Associations between socio-economic factors and the use of prescription medication during pregnancy: A population-based study among 19,874 Danish women. Eur. J. Clin. Pharmacol. 2006, 62, 547-553. [CrossRef] [PubMed]

7. Beyens, M.; Guy, C.; Ratrema, M.; Ollagnier, M. Prescription of drugs to pregnantwomen in France: The HIMAGE study. Therapie 2003, 58, 505-511. [CrossRef] [PubMed]

8. Lacroix, I.; Hurault, C.; Sarramon, M.F.; Guitard, C.; Berrebi, A.; Grau, M.; Albouy-Cossard, C.; Bourrel, R.; Elefant, E.; Montastruc, J.L.; et al. Prescription of drugs during pregnancy: A study using EFEMERIS, the new French database. Eur. J. Clin. Pharmacol. 2009, 65, 839-846. [CrossRef] [PubMed]

9. Egen-Lappe, V.; Hasford, J. Drug prescription in pregnancy: Analysis of a large statutory sickness fund population. Eur. J. Clin. Pharmacol. 2004, 60, 659-666. [CrossRef] [PubMed]

10. Donati, S.; Baglio, G.; Spinelli, A.; Grandolfo, M.E. Drug use in pregnancy among Italian women. Eur. J. Clin. Pharmacol. 2000, 56, 323-328. [CrossRef] [PubMed]

11. Gagne, J.J.; Maio, V.; Berghella, V.; Louis, D.Z.; Gonnella, J.S. Prescription drug use during pregnancy: A population-based study in Regione Emilia-Romagna, Italy. Eur. J. Clin. Pharmacol. 2008, 64, 1125-1132. [CrossRef] [PubMed]

12. Bakker, M.K.; Jentink, J.; Vroom, F.; Van Den Berg, P.B.; De Walle, H.E.; De Jong-Van Den Berg, L.T. Drug prescription pattern before, during and after pregnancy for chronic, occasional and pregnancy-related drugs in The Netherlands. BJOG 2006, 113, 559-568. [CrossRef] [PubMed]

13. Schirm, E.; Meijer, W.; Tobi, H.; de Jong-van den Berg, L. Drug use by pregnant women and comparable non-pregnant women in The Netherlands with reference to the Australian classification system. Eur. J. Obstet. Gynecol. Reprod. Biol. 2004, 114, 182-188. [CrossRef] [PubMed]

14. Engeland, A.; Bramness, J.G.; Daltveit, A.K.; Rønning, M.; Skurtveit, S.; Furu, K. Prescription drug use among fathers and mothers before and during pregnancy. A population-based cohort study of 106,000 pregnancies in Norway 2004-2006. Br. J. Clin. Pharmacol. 2008, 65, 653-660. [CrossRef] [PubMed]

15. Andrade, S.E.; Gurwitz, J.H.; Davis, R.L.; Chan, K.A.; Finkelstein, J.A.; Fortman, K.; McPhillips, H.; Raebel, M.A.; Roblin, D.; Smith, D.H.; et al. Prescription drug use in pregnancy. Am. J. Obstet. Gynecol. 2004, 191, 398-407. [CrossRef] [PubMed]

16. Lacroix, I.; Damase-Michel, C.; Lapeyre-Mestre, M.; Montastruc, J.L. Prescription of drugs during pregnancy in France. Lancet 2000, 356, 1735-1736. [CrossRef]

17. Reimann, I.; Karpinsky, C.; Hoffmann, A. Epidemiological data on drug use during pregnancy in Thuringia, East Germany, 1993. Int. J. Clin. Pharmacol. Ther. 1996, 34, 80-83. [PubMed]

18. Riley, E.H.; Fuentes-Afflick, E.; Jackson, R.A.; Escobar, G.J.; Brawarsky, P.; Schreiber, M.; Haas, J.S. Correlates of prescription drug use during pregnancy. J. Womens Health 2005, 14, 401-409. [CrossRef] [PubMed]

19. Garriguet, D. Medication use among pregnant women. Health Rep. 2006, 17, 9-18. [PubMed]

20. Rubin, J.; Ferencz, C.; Loffredo, C. Use of prescription and non-prescription drugs in pregnancy. J. Clin. Epidemiol. 1993, 46, 581-589. [CrossRef]

21. Headley, J.; Northstone, K.; Simmons, H.; Golding, J. Medication use during pregnancy: Data from the Avon Longitudinal Study of Parents and Children. Eur. J. Clin. Pharmacol. 2004, 60, 355-361. [CrossRef] [PubMed]

22. Zhu, X.; Qi, X.; Hao, J.; Huang, Z.; Zhang, Z.; Xing, X.; Cheng, D.; Xia, L.; Xu, Y.; Zhu, P.; et al. Pattern of drug use during the first trimester among Chinese women: Data from a population-based cohort study. Eur. J. Clin. Pharmacol. 2010, 66, 511-518. [CrossRef] [PubMed]

23. Daw, J.R.; hanley, G.E.; Greyson, D.L.; Morgan, S.G. Prescription drug use during pregnancy in developed countries: A systematic review. Pharmacoepidemiol. Drug Saf. 2011, 20, 895-902. [CrossRef] [PubMed]

24. Mitchell, A.A.; Gilboa, S.M.; Werler, M.M.; Kelley, K.E.; Louik, C.; Hernández-Díaz, S. Medication use during pregnancy, with particular focus on prescription drugs: 1976-2008. Am. J. Obstet. Gynecol. 2011, 205, 51.e1. [CrossRef] [PubMed] 
25. Källén, B.; Borg, N.; Reis, M. The use of central nervous system active drugs during pregnancy. Pharmaceuticals 2013, 10, 1221-1286. [CrossRef] [PubMed]

26. Kawamoto, T.; Nitta, H.; Murata, K.; Toda, E.; Tsukamoto, N.; Hasegawa, M.; Yamagata, Z.; Kayama, F.; Kishi, R.; Ohya, Y.; et al. Rationale and study design of the Japan environment and children's study (JECS). BMC Public Health. 2014, 14, 25. [CrossRef] [PubMed]

27. Obara, T.; Nishigori, H.; Nishigori, T.; Metoki, H.; Ishikuro, M.; Tatsuta, N.; Mizuno, S.; Sakurai, K.; Nishijima, I.; Murai, Y.; et al. Prevalence and determinants of inadequate use of folic acid supplementation in Japanese pregnant women: The Japan Environment and Children's Study (JECS). J. Matern. Fetal Neonatal Med. 2017, 30, 588-593. [CrossRef] [PubMed]

(C) 2017 by the authors. Licensee MDPI, Basel, Switzerland. This article is an open access article distributed under the terms and conditions of the Creative Commons Attribution (CC BY) license (http:/ / creativecommons.org/licenses/by/4.0/). 